\title{
Utilização do método da eletrorresistividade para estimativa de sedimentos transportados por processos erosivos na Bacia do Lago Paranoá
}

Gabriela Nunes Turquetti1, Marcelo Peres Rocha', Márcio Maciel Cavalcanti1, Henrique Llacer Roig', Welitom Rodrigues Borges $^{1}$, George Sand França ${ }^{1}$

1 Instituto de Geociências - Universidade de Brasília

\section{Copyright 2016, SBGf - Sociedade Brasileira de Geofísica}

Este texto foi preparado para a apresentação no VII Simpósio Brasileiro de Geofísica, Ouro Preto, 25 a 27 de outubro de 2016. Seu conteúdo foi revisado pelo Comitê Técnico do VII SimBGf, mas não necessariamente representa a opinião da SBGf ou de seus associados. É proibida a reprodução total ou parcial deste material para propósitos comerciais sem prévia autorização da SBGf.

\section{Resumo}

O presente trabalho teve como objetivo o emprego da geofísica para a estimativa da espessura de sedimentos provenientes de processos erosivos no Braço do Riacho Fundo - DF. Esses processos são consequência direta da ação antrópica, principalmente ocasionada pela ocupação de áreas irregulares sem um planejamento prévio, que vem ocorrendo desde a inauguração de Brasília. O método geofísico aplicado foi a eletrorresistividade, que por sua vez, foi capaz de obter resultados satisfatórios, aproximadamente 5 metros de espessura de sedimentos provenientes desses processos.

\section{Introdução}

O crescimento populacional no Brasil nas últimas décadas, aliado ao crescente processo de desenvolvimento urbano e industrial tem exercido impactos sobre os recursos naturais, principalmente, sobre a água e o solo, acentuando processos erosivos, assoreamento e poluição de mananciais e reservatórios, afetando, dessa maneira, a qualidade e a quantidade de água destinada a população. (Roig, 2005; Echeverria, 2007).

Mudanças nos padrões de uso e ocupação em uma bacia hidrográfica podem acarretar uma série de consequências no ciclo hidrológico da bacia (Tucci, 2007; Heller \& Pádua, 2006; Setti et al., 2001). Um exemplo que merece destaque é o caso da Bacia do Lago Paranoá no Distrito Federal. Segundo Assel \& Cldf (1999), a conservação dos mananciais hídricos das bacias do Lago Paranoá está comprometida pelo mau uso do solo, decorrência de assentamentos, loteamentos e condomínios construídos de forma irregular e que ocupam, geralmente, áreas de conservação ambiental e áreas rurais sem planejamento prévio.

Assim, o lago está submetido a uma elevada e constante pressão antrópica, não somente pelas inúmeras atividades concentradas ao longo das suas margens, mas também pela degradação das bacias hidrográficas dos tributários (Menezes, 2010).

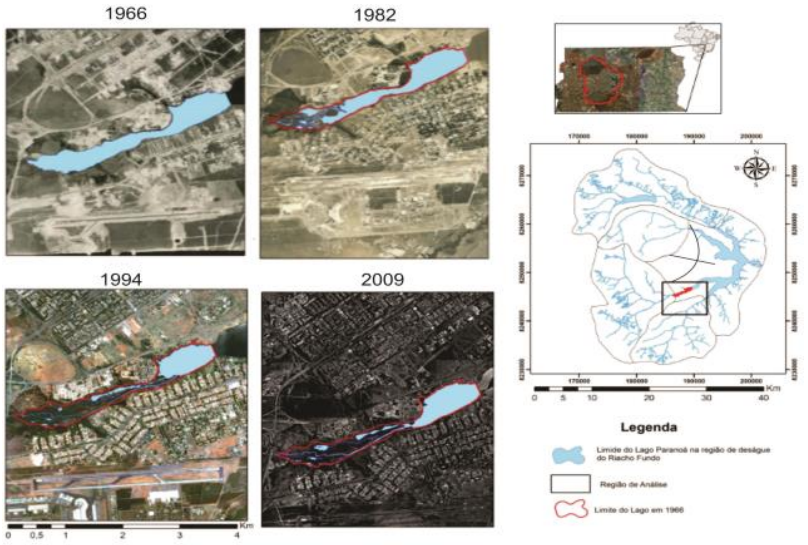

Figura 1 - Braço do Riacho Fundo e os seus avanços dos processos sedimentares ao longo dos anos. Adaptado: Menezes, 2007.

Neste contexto, destaca-se o caso do Braço do Riacho Fundo, situado na porção sudeste da Bacia do Lago Paranoá. Esse braço em particular possui uma fragilidade maior se comparado com os outros, devido ao fato de que desde a construção de Brasília, sua área foi ocupada, a uma alta taxa de urbanização desde 1954, com salto no ano de 1994 (Menezes, 2010), resultando em um processo de assoreamento acentuado do Lago Paranoá nessa região (Figura 1).

$\mathrm{O}$ entendimento do processo de assoreamento, bem como a estimativa do volume de sedimentos assoreados são importantes para a gestão do problema, e também em tomadas de decisões por parte do poder público, para problemas semelhantes em outras regiões.

Neste contexto, as ferramentas geotecnológicas se apresentam eficientes na obtenção de informações sobre as causas e consequências desse tipo de processo. Entre as metodologias mais comuns aplicadas a esse tipo de problema, destaca-se o Geoprocessamento (e.g. Menezes, 2010) e mais recentemente a Geofísica.

Neste trabalho, o método geofísico da eletrorresistividade foi aplicado com o objetivo de estimar a espessura dos sedimentos assoreados no Braço do Riacho Fundo, e comparar os resultados obtidos com trabalhos anteriores de geoprocessamento na região. A área de estudo está localizada no Braço do Riacho Fundo no encontro deste próximo ao início do Lago Paranoá nas proximidades da Vila Telebrasília (Figura 2).

\section{Metodologia}

Para esse trabalho, o método geofísico utilizado foi a eletrorresistividade, que consiste na injeção de corrente elétrica contínua no solo, onde a mesma é transmitida por um par de eletrodos de corrente, ligados a uma fonte. 


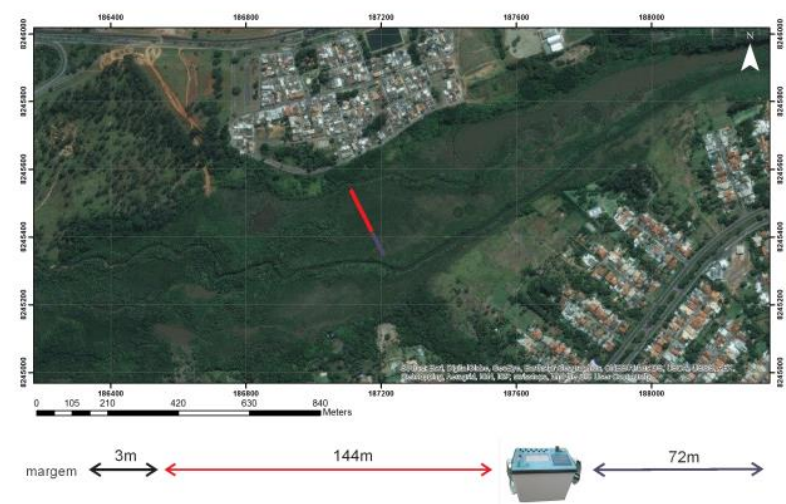

Figura 2 - Localização da área de estudo

A Figura 2 ilustra as duas linhas adquiridas com 0 método da eletrorresistividade. As linhas de aquisição foram ambas realizadas no sentido NW-SE, onde a linha 1 corresponde ao cabo com 72 canais possuindo 144 metros de comprimento e a linha 2 corresponde ao cabo com 36 canais possuindo 72 metros de comprimento.

Os arranjos adotados foram o Dipolo-Dipolo e o Wenner, com espaçamento de 2 metros entre os eletrodos. Tais arranjos foram escolhidos para fins de comparação e por serem os que têm maior resolução lateral $e$ de profundidade, respectivamente, e que no processamento podem ser eventualmente, combinados.

No pré-processamento dos dados (controle de qualidade) foi utilizado o programa Prosys II, da Iris Instruments, com o objetivo de remover valores atípicos de resistividade aparente, corrente e diferença de potencial e que possam causar ambiguidades aos resultados após o processo de inversão.

Para o processamento dos dados, foi utilizado o programa Res2dinv, da GEOMOTO SOFTWARE, onde é gerado o modelo de resistividades aparentes a partir da inversão e onde são incluídas as informações a priori disponíveis, como por exemplo, em nosso caso, os valores de resistividade da água presente no local da aquisição, devido a alguns eletrodos estarem submersos, o intervalo entre eles e a espessura da lâmina d'água.

\section{Resultados e Discussão}

Os resultados obtidos nesse trabalho para os dois arranjos estão apresentados nas Figuras 3 a 5 . Observou-se que as profundidades alcançadas para ambos os arranjos foi baixa, quando comparada com a profundidade de investigação teórica (Braga, 2007).

Mesmo para o arranjo Wenner, que tende a atingir maiores níveis de investigação, as profundidades foram baixas, comparáveis com aquelas alcançadas pelo Arranjo Dipolo-Dipolo (que tende a ser mais raso), ainda com a desvantagem de ter uma perda lateral significativa (Figura 4), que é característica desse arranjo (Loke, 2010). Provavelmente, devido à alta condutividade da primeira camada que está saturada de água, a corrente injetada tendeu a se propagar de forma horizontal, dificultando a sua propagação vertical, prejudicando 0 imageamento das camadas subjacentes.

Apesar das altas condutividades da camada superficial, foi possível identificar duas camadas com contraste de significativo de resistividades. A interface entre as duas chega até 6 metros de profundidade (Figuras 3 e 4), sendo que a primeira camada possui resistividades no intervalo de 10 a $114 \Omega \mathrm{m}$, e deve estar associada ao horizonte de sedimentos saturados transportados pelo processo de assoreamento do Braço do Riacho Fundo. A segunda camada possui resistividades mais altas no intervalo de 256 a $1297 \Omega \mathrm{m}$, e deve estar relacionada com o material original do fundo do lago.

Com base nos resultados obtidos, considerando uma espessura média de 5 metros dos sedimentos assoreados podemos estimar que durante cerca de 55 anos desde a inauguração de Brasília, houve uma taxa média de assoreamento de 9 centímetros por ano devido a ocupação da cidade. No entanto, essa taxa não foi linear ao longo do tempo, pois segundo Carneiro (2013) houve um aumento dessa taxa nos últimos 4 anos no Braço do Riacho Fundo, com a pluma sedimentar tendo um avanço de 160 metros em direção ao Lago Paranoá, com uma variação de espessura de 3 metros.

Conforme Menezes (2010), o assoreamento do Braço do Riacho Fundo está relacionado com a ocupação não planejada de toda a sua bacia hidrográfica, tendo esse processo se tornado crítico no início dos anos 90 e se intensificado desde o início de 2009, o que explica os resultados apresentados por Carneiro (2013) e os observados nesse trabalho.

Para se obter uma visão mais completa do quadro de assoreamento em que se encontra o Braço do Riacho Fundo seria interessante a realização de levantamentos paralelos aos feitos nesse trabalho, o que daria uma visão volumétrica mais adequada do acúmulo de sedimentos além, da integração dos resultados dos diversos trabalhos da região.

\section{Conclusões}

O método da eletrorresistividade apresentou viável para a definição da espessura de sedimentos provenientes do assoreamento do Braço do Riacho Fundo especialmente por esses se encontrarem saturados, o que favorece a aplicação desse método.

Foram observadas duas camadas com características geoelétricas distintas, sendo a mais superficial com alta condutividade devido a estar saturada e a subjacente de menor condutividade.

A espessura média da camada de sedimentos assoreados, estimada com os resultados obtidos, é de cerca de 5 metros, na altura onde foi realizado o levantamento.

A partir dos resultados pode-se estimar uma taxa de sedimentação da ordem de 9 centímetros por ano, a qual, apesar de não ser constante e não refletir os picos de ocupação da Bacia do Riacho Fundo, causa preocupação.

\section{Agradecimentos}

Ao LGA/UnB pela concessão do equipamento necessário para a realização desse trabalho, e aos membros da PhyGeo - Soluções em Geofísica e Geotecnologia, Empresa Junior dos alunos de graduação em Geofisica da Universidade de Brasília, pelo grande apoio durante a 
execução da aquisição dos dados no Braço do Riacho Fundo.

\section{Referências}

ASSEL \& CLDF. A força do entorno elaborado pela Assessoria Legislativa (ASSEL) da Câmara Legislativa do Distrito Federal (CLDF), 1999.

Echeverria, R. M., Avaliação de Impactos Ambientais nos Tributários do Lago Paranoá, Brasília - DF. Dissertação (Mestrado) 2007 - Instituto de Geociências, Universidade de Brasília.

Heller, L.; Pádua, W. L. de. Abastecimento de Água para Consumo Humano. Belo Horizonte: UFMG, 2006. 859p.

Loke, M.H., Wilkinson, P. and Chambers, J., 2010. Fast computation of optimized electrode arrays for 2D resistivity surveys. Computers \& Geosciences, 36, 14141426.

MENEZES, P. H. B. J. Avaliação do efeito das ações antrópicas no processo de escoamento superficial e assoreamento na Bacia do Lago Paranoá. Dissertação de Mestrado - Universidade de Brasília - UnB, Brasília-DF. 2010.

Roig, H.L. 2005. Modelagem e Integração de processos erosivos e do transporte de sedimentos - O caso da Bacia do Rio Paraíba do Sul. Tese de Doutorado. IG UnB. 215p.

Setti, A. A.; Werneck Lima, J. E. F.; Miranda Chaves, A. G.; Castro Pereira, I. C. Introdução ao Gerenciamento de Recursos Hídricos. Agência Nacional de Energia Elétrica (ANEEL). Agência Nacional de Águas (ANA). Brasília, DF, 2001. 398p.

Tucci, C. E. M., Escoamento Superficial. In: Tucci, C. E. M., Hidrologia: Ciência e Aplicação. 4 ed. Porto Alegre: UFRGS/ Associação Brasileira de Recursos Hidricos, 2007. Cap. 11, p. 391-442. 


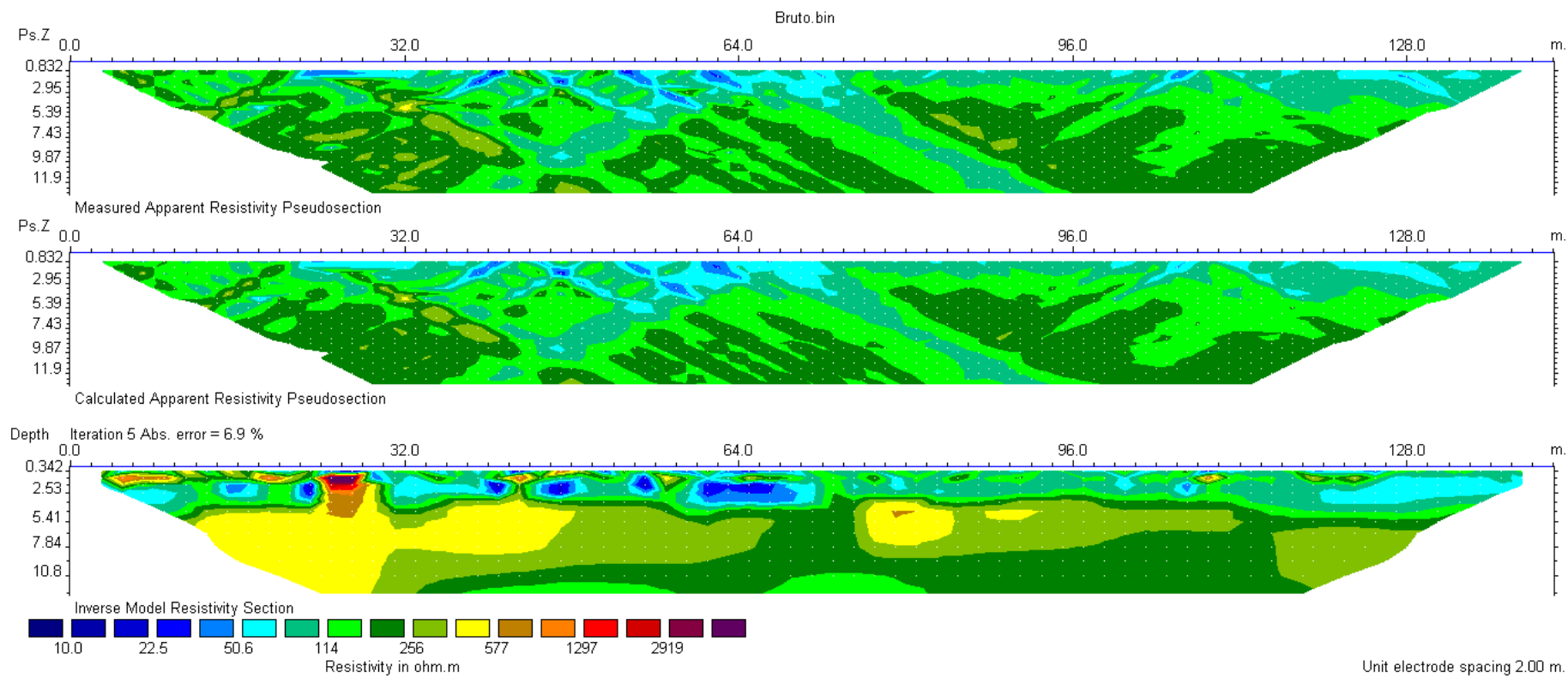

Figura 3 - Seção de eletrorresistividade da linha 1 (72 canais) com o arranjo Dipolo-Dipolo
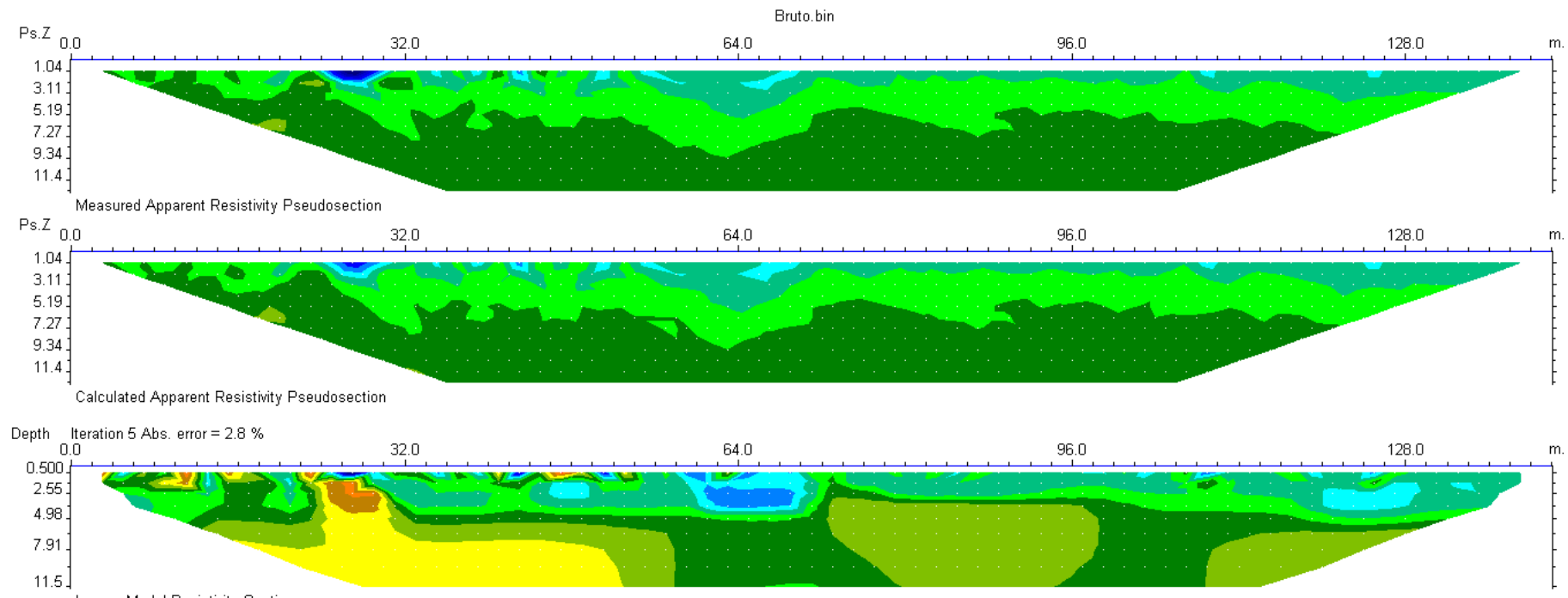

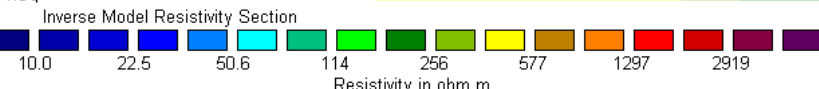

Figura 4 - Seção de eletrorresistividade da linha 1 (72 canais) com o arranjo Wenner 

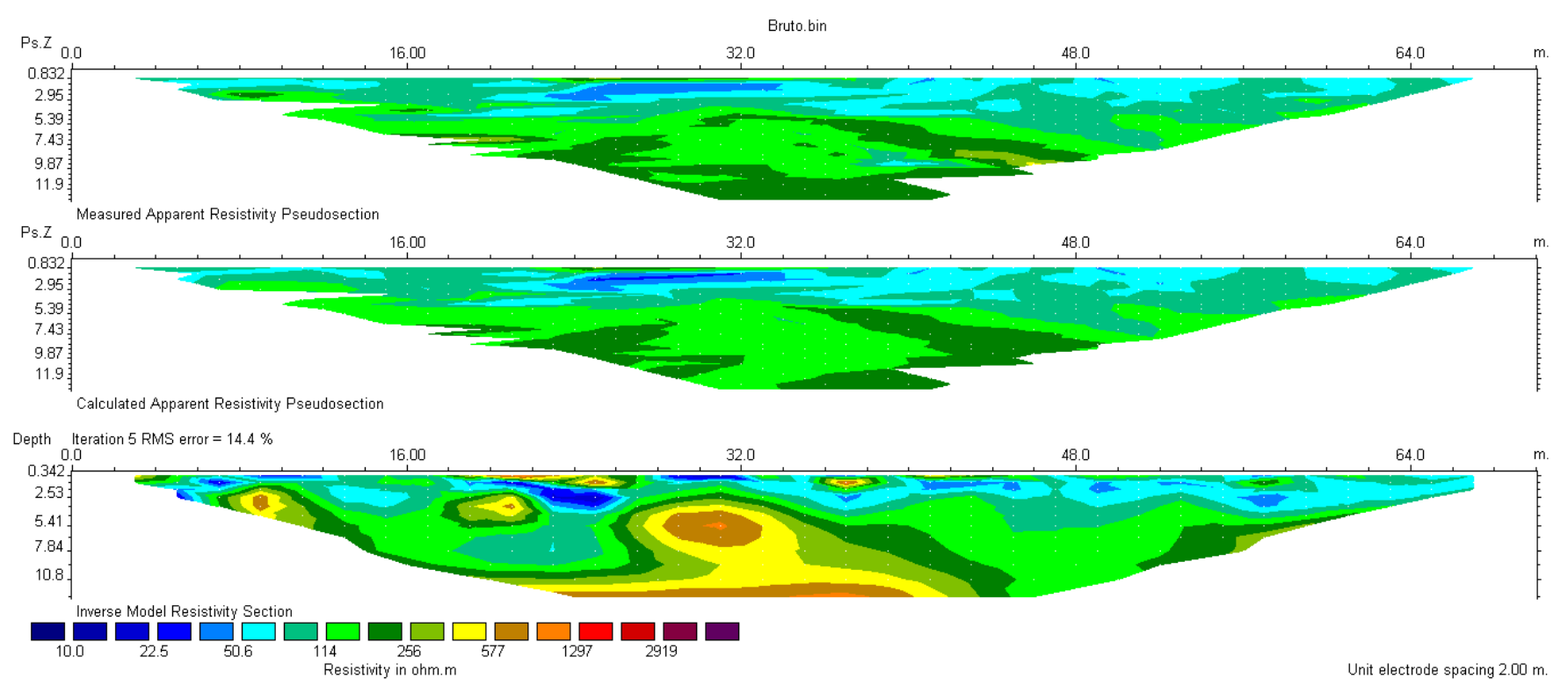

Figura 5 - Seção de eletrorresistividade da linha 2 (36 canais) com o arranjo Dipolo-Dipolo 